\title{
"Só é fracassado quem quer": a subjetividade loser na literatura de autoajuda
}

Mayka Castellano

Resumo: Neste artigo, a partir da análise do livro Só é fracassado quem quer, exemplar da literatura de autoajuda escrito por Thomas Morgan e publicado no Brasil em 1989, proponho a problematização da recente incorporação no país do discurso desabonador a respeito do fracasso, situação entendida não como resultado de um contexto social específico, mas como inadequação individual. Para isso, parto da abordagem sobre uma figura marcante da cultura norte-americana: o loser, presente em diversos produtos culturais daquele país, e que, no Brasil, aparece traduzido pelo termo fracassado. O fracassado, nesse sentido, simboliza aquele que não prosperou em um pretenso mundo de oportunidades difundido pelo imaginário do sucesso da autoajuda contemporânea.

Palavras-chave: autoajuda; análise de discurso; fracasso; fracassado; sucesso.

Abstract: "Failure is a matter of choice": the loser subjectivity in self-help literature - In this paper, based on the analysis of "Só é fracassado quem quer", a self-help literature book written by Thomas Morgan and published in Brazil in 1989, I problematize the recent incorporation of the derogatory speech about failure in this country, which is perceived not as an outcome of a specific social context, but as individual inadequacy. For such, I start by approaching a striking figure in American culture: the loser, found in many of its cultural products and often translated as "fracassado" in Brazil. The "fracassado", in this sense, symbolizes the one who has not succeeded in an alleged world of opportunities widespread by the imagery of success that is reflected in the ethos of contemporary self-help.

Keywords: self-help; discourse analysis; failure; loser; success.

"A história é escrita pelos vencedores". A célebre frase atribuída a George Orwell poderia certamente ser reelaborada sem perder seu tom de constatação: a história dos vencedores é que é escrita. Todo o ethos formado pela literatura de autoajuda, 
dos clássicos livros de Samuel Smiles ${ }^{1}$ e Swett Marden, produzidos no século XIX, aos contemporâneos best-sellers, assim como a maior parte das biografias e cinebiografias narram trajetórias de sujeitos que prosperaram.

O mundo, no entanto, está repleto de fracassados, que também têm uma história para contar. Motivado por essa invisibilidade das existências sem brilho, Foucault escreveu "A vida dos homens infames" (2003). Nesse texto, o autor se dedica a comentar a existência de pequenos relatos encontrados em documentos oficiais (sobretudo ordens de prisão ou internamento) dos séculos XVII e XVIII, recortes de vidas "dotadas de nenhuma dessas grandezas estabelecidas e reconhecidas - as do nascimento, da fortuna, da santidade, do heroísmo ou do gênio" (ibid., p. 206).

As "pessoas absolutamente sem glória" (ibid., p. 208), que protagonizam o texto, não têm em seus currículos nem a infâmia honrosa daqueles que despertam o medo ou o horror, suas trajetórias são "destinadas a passar sem deixar rastro", sem "que houvesse em suas desgraças, em suas paixões, em seus amores e em seus ódios alguma coisa de cinza e de comum em relação ao que se considera, em geral, digno de ser contado (ibid., p. 206).

Foi também baseado nessa ideia que o americano Scott Sandage escreveu o livro Born losers: a history of failure in America (2005), fruto de sua pesquisa de doutorado. Na obra, o autor se dedica justamente a revelar as histórias de vida daqueles que feneceram. Mas, aqui, seu foco recai sobre seus compatriotas que foram vítimas de um sistema econômico onde o jogo pressupõe poucos vitoriosos. "Esse livro conta a história de fracassados desconhecidos da América: homens que falharam em uma nação que venera o sucesso" (ibid., p. 3; tradução nossa)², resumiu.

Desde a publicação das primeiras edições baratas da autobiografia de Benjamin Franklin, na década de 1840, milhares de manuais de autoajuda, folhetos inspiradores, e estudos têm brindado o sucesso. Livros sobre perdedores são poucos e intermitentes. Estagnado politicamente na década de 1850, Abraham Lincoln lamentou: "Os homens são gananciosos por publicar os sucessos dos [seus] esforços, mas mesquinhamente tímidos quanto à publicação das falhas. Homens são arruinados por essa prática da ocultação de erros e fracassos". (Ibid., p. 8; tradução nossa) $)^{3}$

1 Ao buscarmos a gênese da autoajuda, frequentemente nos deparamos com menções à antiguidade clássica, às "regras de bem viver" propostas por alguns pensadores, aos livros de interpretação dos sonhos que, como nos lembra Foucault, funcionavam, nos primeiros séculos de nossa época, como "técnicas de vida" (1985, p. 14), "manuais de vida" (p. 15) ou, ainda, aos numerosos tratados, manuais e documentos produzidos ao longo do século XVIII e que tinham como objetivo discutir os melhores caminhos para a boa vida e a felicidade. A maior parte dos pesquisadores, no entanto, definiu como fundador do gênero o autoexplicativo Self-Help, de Samuel Smiles, publicado em 1859, na Inglaterra (CASTELLANO, 2014a).

2 "This book tells the story of America's unsung losers: men who failed in a nation that worships success"

3 "Since the publication of the first cheap editions of The Autobiography of Benjamin Franklin in the 1840s, thousands of self-help manuals, inspirational tracts, and learned studies have toasted success. Books about losers have been few and far between. Stalled politically in the 1850s, Abraham Lincoln moaned, 'Men are greedy to publish the successes of [their] efforts, but meanly shy as to publishing the failures of men. Men are ruined by this one sided practice of concealment of blunders and failures". 
A pesquisa de Sandage (2005) se concentrou basicamente no século XIX, quando o empreendedorismo se tornou o modelo principal de identidade norte-americana e o self-made man sua epítome, e, ao mesmo tempo, crises econômicas levaram à bancarrota milhões de empresários. Foi nessa época que o fracasso deixou de significar apenas a falência nos negócios e passou a designar o resultado de toda uma vida. Mais do que um problema financeiro, transformou-se em uma falha de caráter. No dicionário da língua inglesa Webster, publicado em 1828, a definição de failure fornecida era "a breaking or becoming insolvent"4 , já na edição de 1857, o vocábulo aparecia como "some weakness in a man's character, disposition or habit" ${ }^{5}$ (apud SANDAGE, 2005, p. 11-12).

O fracasso havia se tornado o que continua sendo no novo milênio: a encarnação mais contundente da conexão entre realização e identidade pessoal. "Eu me sinto um fracasso". A expressão é tão natural que nos esquecemos que é uma figura de linguagem: a linguagem dos negócios aplicada à alma. (Ibid., p. 5; tradução nossa) ${ }^{6}$

As próprias designações winner e loser se popularizaram nessa época, já que eram esses os termos utilizados por instituições burocráticas como agências de crédito, comissões de falência e escritórios de caridade para classificar as pessoas de acordo com o tipo de demanda. Se em português essas expressões soam um tanto fortes, é importante notar que, em inglês, o caminho seguido por elas foi justamente esse: de expressões ligadas às finanças passaram a integrar o léxico do dia a dia. Nesse sentido, vale lembrar que a palavra fail se refere, ao mesmo tempo, a falir e fracassar, vocábulos que, na língua portuguesa, preservam sentidos expressivamente distintos.

O século do destino manifesto foi o palco de muitas tragédias não narradas, analisadas por Sandage (2005) através de diários, correspondências, relatos de descendentes e documentos que trazem a constatação de que o número de suicídios crescia expressivamente nos momentos em que o sonho americano se transformava para muitos em pesadelo. Essa máxima se manteve durante o século $X X$, quando, durante a crise de 1929, muitos sucumbiram. A explicação para tais tragédias pode ser encontrada no fato de que o fracasso ressoava cada vez mais como um problema interno do indivíduo, logo, tempos difíceis e crises econômicas não serviam como desculpa suficiente, como justificativa para não ter conseguido "chegar lá".

Durante o período de elaboração do livro, Sandage (ibid.) reuniu depoimentos de pessoas que se autointitulavam losers e de parentes de indivíduos que sofreram com esse estigma. Em uma das cartas que recebeu, um homem, morador do estado do Colorado,

\footnotetext{
" falência ou tornar-se insolvente"

"alguma fraqueza no caráter de um homem, disposição ou hábito"

"Failure had become what it remains in the new millennium: the most damning incarnation of the connection between achievement and personal identity. "I feel like a failure." The expression comes so naturally that we forget it is a figure of speech: the language of business applied to the soul"
} 
Ihe confidenciou: "Por falta de ganância, crueldade, agressividade, carisma e outras 'qualidades' norte-americanas exigidas, estou condenado a... acordar aterrorizado todas as noites" (ibid., p. 260; tradução nossa) ${ }^{7}$.

Das primeiras décadas do século XX até os dias atuais, tal imaginário ganhou cada vez mais terreno. Essa concepção estrita e institucionalizada de sucesso tem sua dinâmica original circunscrita aos processos de management (e, portanto, ligada a questões como mercado, metas, lucro, concorrência). A busca por sua gênese nos EUA se justifica no fato de identificarmos nesse país o desenvolvimento desse imaginário. Sentir-se como um perdedor naquele contexto significava ir de encontro à principal imagem almejada pelos americanos, que ao longo de sua história acompanharam a formação mítica do vencedor, sujeito que constrói seu próprio caminho, e, independentemente do contexto social que o cerca, prospera. Parte dessa mitologia começou a ser moldada ainda na época da colonização inglesa e da formação da então incipiente sociedade norte-americana, em que desempenhou um papel decisivo a religião (DECKER, 1997; WEBER, 1999; CATANO, 2001).

A chegada desse imaginário ao Brasil foi favorecida pela propagação, aqui, de um discurso imperativo sobre a necessidade de modernização e progresso do país, sobretudo no que se referisse aos processos organizacionais, o que trouxe no seu bojo não apenas imposições sobre questões práticas, mas também novos valores, formas de pensar, crenças e visões de mundo. A incorporação dessa noção na cultura brasileira se dá concomitantemente à adoção de um modelo de desenvolvimento capitalista próximo ao que marcou o crescimento da economia dos Estados Unidos, ou seja, fortemente baseado no consumo e cada vez mais impregnado pela mentalidade neoliberal e suas correlatas concepções de autonomia e responsabilidade individual.

Uma das principais formas de materialização dessa influência se deu através da chegada ao país das publicações de autoajuda, gênero que comporta uma impressionante variedade de temas, que apresentam como característica comum o objetivo de aconselhar/guiar o leitor em suas práticas diárias e em suas relações consigo mesmo e com os outros. Isto é, são livros que fornecem dicas, manuais, reflexões que pretendem auxiliar os indivíduos a tomarem decisões e a pautarem seu comportamento, com o propósito de garantir um aprimoramento emocional, profissional, espiritual, intelectual, financeiro, normalmente a partir da opinião abalizada de autoproclamados especialistas.

A maior parte dos livros de autoajuda ${ }^{8}$ consagrada à temática do sucesso apela, no título, para o campo semântico ligado ao vencedor, e não à sua antítese. Poucos livros

7 "For lack of greed, ruthlessness, extreme aggression, charisma and other required US 'qualities,' I am doomed to... wake in terror every night"

8 Este artigo é parte de minha pesquisa de doutorado (CASTELLANO, 2014b), em que analisei a articulação e a expansão da vitória como um imperativo socialmente validado. A partir de um arsenal teórico formado por autores que se propuseram a pensar as transformações na moral contemporânea, avaliei exemplares da literatura de autoajuda, principal materialização cultural desse imaginário. Com o objetivo de compreender os discursos que são mobilizados através desse gênero e que contribuem para a produção de subjetividade na contemporaneidade, sobretudo através das figuras do vencedor e do fracassado, privilegiei obras de duas épocas distintas: duas produzidas no século XIX, precursoras do gênero, e seis produzidas a partir dos anos 1980. Dentre elas, a única dedicada ao fracassado e não ao vencedor é Só é fracassado quem quer, analisada neste artigo. 
sobre o sucesso trazem o fracasso no título, mesmo que seja para se referir a ele como algo a ser evitado a todo custo. Neste artigo, no entanto, dedicar-me-ei a um exemplar que foge a essa regra e se empenha em aconselhar a partir da construção da imagem opositiva do fracassado. Para isso, empreendo uma análise de discurso de inspiração pós-estruturalista, que privilegia o conteúdo e o contexto da linguagem e não sua estrutura.

Dessa forma, encaro o discurso a partir das relações de poder específicas, historicamente constituídas, que ele engendra e das noções particulares de verdade que ele invoca (FOUCAULT, 1995), principalmente no que se refere ao processo de desnaturalização dos aconselhamentos propostos pela autoajuda. Ou seja, as premissas formuladas no âmbito desse tipo de produção editorial não são atemporais nem revelam padrões de comportamento que sempre foram encarados como válidos. Pelo contrário, creio que uma investigação adequada desse fenômeno pode trazer interessantes contribuições justamente para pensarmos traços peculiares da contemporaneidade. Assim, meu principal objetivo ${ }^{9}$ é problematizar determinados discursos a respeito do fracasso que circulam atualmente no gênero da autoajuda.

\section{O fracasso como opção}

Na literatura de autoajuda, é muito comum a crença de que uma vida bem-sucedida é questão de escolha. Algumas obras, no entanto, levam essa noção às últimas consequências. Esse é o caso de Só é fracassado quem quer, de Thomas Morgan, publicado em 1989. Nela, o autor inicia a narrativa com a história do espermatozoide vencedor:

[O] homem no momento do ato sexual, quando ejacula, descarrega milhões de espermatozoides no canal vaginal da mulher, e apenas um único é que conseguirá agarrar-se ao óvulo, para daí transformar-se após nove meses em um novo ser humano. Isto não é incrível? Em qualquer livro de Biologia, você poderá saber mais sobre este fascinante assunto. O mais fantástico em tudo isso é que você resulta deste milagre. Você foi o óvulo e o espermatozoide destinados a vencer a impressionante batalha da vida. Milhões de outras células morreram por não conseguirem o propósito da criação, mas você foi vencedor do primeiro concurso da sua existência. Parabéns por este feito. (MORGAN, 1989, p. 9-10)

O contorcionismo retórico serve para transformar o fenômeno natural da concepção em mais do que algo "incrível", "fantástico", "fascinante", "impressionante", mas em prova irrefutável de que você está fadado ao sucesso. Você, pois, embora essa seja uma das questões comuns a todos os seres humanos, aqui ela é tratada como algo individual e digno de congratulação.

9 Vale ressaltar que minha pesquisa tem como objeto os discursos encontrados nos livros de autoajuda, dessa forma, não está entre os meus objetivos avaliar a recepção desses livros, os seus possíveis usos e assimilações. 
Logo nas primeiras páginas, Morgan (ibid.) apresenta uma história que marcará a tônica do livro. Ele conta que estava hospedado em um hotel frequentado por "turistas endinheirados" quando foi abordado por um "rapaz maltrapilho" (ibid., p. 12). Indignado com o fato, em vez de dar dinheiro ao homem, preferiu ouvir sua história, que ele narra da seguinte forma:

O rapaz se chamava Miguel, tinha 34 anos, 6 filhos menores e seu pai falecera quando completara 11 anos. A mãe, incapaz de sustentar 8 filhos, obrigava os meninos a pedir esmola, para não morrerem de fome. O tempo passou, Miguel acostumou-se a pedir esmola desde os 11 anos, até que conheceu uma outra mulher que também esmolava no mercado público e com ela teve 6 filhos, os quais também pediam esmolas pelas ruas da cidade. Viviam amontoados num barraco imundo, sem conforto, e a maior parte do tempo perambulavam pelas ruas, estendendo a mão e recebendo sobras de comida alheia. Miguel culpava a mãe por tê-lo ensinado a esmolar desde pequeno, e ao governo que não ajudava os pobres. Provavelmente seus filhos o culparão no futuro, e os netos acharão alguém para ser responsabilizado pela vida miserável e fracassada que tiveram. (Ibid., p. 12)

É notável como nesse livro a figura do mendigo é eleita como o Outro preferencial, o protótipo mais bem acabado do fracasso. Não é à toa que a certa altura do texto o autor ache de bom tom fazer a seguinte ressalva: "Não são os mendigos os únicos fracassados" (ibid., p. 13).

Na história acima citada, uma das inúmeras que têm um pedinte como protagonista, fica clara a crença no poder individual e na capacidade de o sujeito transformar a própria trajetória, a despeito do cenário que o cerca e dos antecedentes que marcaram sua vida. Imputar a culpa pela miséria aos outros, seja ao governo ou aos pais, é encarado como algo absurdo e fortemente condenável, além de configurar como uma incontestável insígnia do fracasso: "Nunca encontrei um único mendigo que culpasse a si mesmo pela vida fracassada. Ser fracassado na vida é viver culpando os outros da própria infelicidade" (ibid., p. 13).

A ideia de uma divisão da sociedade entre vencedores e fracassados surge aqui sem rodeios: "No mesmo restaurante que você almoça ou parque infantil onde passeia com a família, existem dois tipos de pessoas: as fracassadas e as de sucesso" (ibid., p. 13). É interessante como o termo fracassado já é usado aqui com tanta naturalidade, antes mesmo de sua maior circulação no Brasil, que só vai ocorrer a partir do final dos anos 1990, quando a autoajuda se consolida como o filão de maior sucesso no mercado editorial.

Em uma descrição que ressoa uma leitura enviesada da noção de distinção proposta por Bourdieu (2007), o autor afirma que é possível identificar os fracassados através de alguns sinais, observáveis através de sua postura, de seus modos de consumo e estilos de vida: "são pessoas que usam roupas de terceira categoria", "ao escolherem uma refeição no cardápio, olham primeiro o lado direito, onde estão os preços, para em seguida fazerem a escolha", "andam cabisbaixos, ostentam um sorriso amarelado de desânimo e fracasso", 
"a família dos fracassados anda com timidez e vergonha de estarem num lugar público", "os filhos dos fracassados olham com inveja para os filhos dos ricos e suspiram de infelicidade por não terem os patins, skate ou bicicleta com que tanto sonham" (Ibid., p. 13).

Em A distinção: Crítica social do juízo (2007), Bourdieu, com base em dados levantados por pesquisas empíricas sobre padrões de consumo na França, nas décadas de 1960 e 1970, desenvolve uma complexa tese que salienta a centralidade do consumo nas práticas sociais. Bourdieu relativiza a importância das propriedades materiais e situa a posse de capital simbólico (cultural) como principal fator de distinção dentro da sociedade. Dessa forma, o consumo passa a desempenhar um papel central na criação e manutenção de relações sociais de dominação e submissão e é justamente nessa disputa por poder e status — que ocorre tanto no interior das classes quanto no conjunto da população - que o autor francês está interessado.

Cultura, dessa forma, é entendida como uma economia onde os indivíduos investem e acumulam capital. Da mesma forma que no mercado econômico, no cultural alguns gostos são mais valorizados que outros e determinadas atitudes ajudam certos grupos a obter prestígio no convívio social. Um conceito de extrema importância na obra de Bourdieu é o habitus, um sistema de disposições que funciona como uma matriz de percepções, apreciações, julgamentos e ações que torna possível a realização das mais diferentes tarefas. Reproduzido entre gerações, o habitus estabelece esquemas por meio dos quais os objetos são diferenciados e classificados (ibid.).

Assim como a noção de capital cultural, o habitus começa a ser moldado ainda na fase da infância, de acordo com o conjunto de condições materiais disponíveis, e opera abaixo do nível de consciência do indivíduo, que faz escolhas pautado por uma falsa impressão de "naturalidade". Assim, a predileção de determinados sujeitos por específicos objetos considerados de "bom gosto" é encarada como uma espécie de "dom", quando, na verdade, trata-se da ativação de uma série de mecanismos engendrados pela construção constante do discernimento de práticas valorizadas ao longo de toda sua vida (ibid.).

O habitus é, portanto, um dos princípios fundadores da ideia de gosto. A maneira com que os sujeitos vão dispor as distinções dicotômicas (bom/ruim; elegante/brega, refinado/ popularesco, de alto/baixo nível) ajuda a compor a noção de gosto aparentemente pessoal, mas, na verdade, reflexo de um quadro de referência que dá conta de uma experiência social específica (e, por isso, passível de disputas).

É oportuno, nesse ponto, resgatarmos o uso que Souza (2006) faz dessa obra. O pesquisador brasileiro entende que a principal contribuição da sociologia de Bourdieu consiste na sistemática desconstrução da ideologia que serve de base ao consenso social e político das sociedades centrais ocidentais, sociedades que, nas palavras do autor "hierarquizam implicitamente o tempo todo, mas possuem explícito 'horror à hierarquia' e que têm na igualdade seu valor máximo" (ibid., p. 87). 
Em outras palavras, ao revelar a desigualdade que subjaz sob a crença na lógica do desempenho e da meritocracia, tão caras à autoajuda, expondo como pré-construídas por origem e herança qualidades que se pretendem inatas, o sociólogo francês atinge no âmago a "hierarquia legítima" (ibid.) afiançada pela mentalidade meritocrática.
A "ideologia do desempenho" funcionaria assim como uma espécie de legitimação subpolítica incrustada no cotidiano, refletindo a eficácia de princípios funcionais ancorados em instituições opacas e intransparentes como mercado e Estado. Ela é intransparente posto que "aparece" à consciência cotidiana como se fosse efeito de princípios universais e neutros, abertos à competição meritocrática. (Ibid., p. 170)

Voltando à análise do livro de Morgan, anos antes de o programa Esquadrão da Moda se propor a reformular a vida de candidatos à repaginação através da mudança no guarda-roupa, Morgan aconselhava seus leitores a investirem no vestuário para passar uma imagem vencedora: "Arranque [do armário] tudo que for ultrapassado e esteja fora de moda. Apegue-se à boa aparência, nunca a roupas antigas ou muito usadas (...). Faça com que sua aparência de sucesso lhe atraia sucesso" (1989, p. 85). Além das roupas, é necessária também uma mudança de atitude: "Adquira uma postura de quem venceu na vida. Ande com os ombros nivelados, a cabeça aprumada, o olhar para frente" (p. 86).

O trecho mais complicado do livro, no entanto, aparece quando o autor desenvolve a tese de que "algumas pessoas acham que pedir esmolas é um bom negócio" (ibid., p. 14). O argumento aqui é rasteiro. A mendicância é encarada como uma escolha, como se as pessoas a elegessem, diante de inúmeras possibilidades; como se optassem, por exemplo, entre ser médico, engenheiro ou mendigo. A alegação usada por Morgan baseia-se em uma espécie de "lenda urbana" bastante difundida, sobretudo entre as alas mais conservadoras da sociedade: a existência de pedintes ricos.

\begin{abstract}
Cheguei a comprovar a existência de um homem aos 42 anos de idade, morando numa casa bem mobiliada, com televisão em cores, videocassete [vale lembrar que o livro é de 1989], aparelho de som moderno, sem falar no modesto mas conservado carro de passeio que mantinha na garagem, cuja atividade nada mais era que de MENDIGO. Sofria de paralisia de membros inferiores, ${ }^{10}$ e isto foi suficiente pra que se atirasse à mendicância até os dias de hoje. Entretanto, para pedir esmolas, veste-se com trajes sujos e rasgados, arrastando-se pelas ruas, a implorar com as mãos e o olhar piedoso: "uma esmolinha pelo amor de Deus...". (Ibid., p. 14)
\end{abstract}

Apesar de ser apresentada como um caso específico, tal realidade é expandida na análise do fenômeno da mendicância, e serve de justificativa para validar a opinião de

10 O falso mendigo, de tão bem-sucedido, provavelmente tinha condições de adquirir um carro adaptado para portadores de deficiência física, já que possui um automóvel, embora tenha paralisia nas pernas. 
que ser fracassado/pobre é uma escolha. Essa concepção pode ser verificada, também, numa espécie de mantra repetido por pessoas que compartilham a mentalidade do autor, quando, diante de um pedinte, sugerem, mesmo que mentalmente, coisas como "vai lavar uma roupa, arrumar um emprego", embora seja difícil imaginar que algum deles estivesse disposto a oferecer, de fato, um serviço ao mendicante. "Implorar por uma esmola é algo tão humilhante e deprimente que só os fracassados de verdade se submetem a esta prática" (1989, p. 14), afirma o autor a certa altura, para depois ir além:

Nem os próprios animais, desprovidos de inteligência, ficam à espera de quem Ihes dê esmolas. Os gatos saem à caça dos ratos e não há ninguém que tenha visto um rato ou gato numa esquina pedindo esmola. Os ratos são vaidosos e orgulhosos demais para adularem a caridade alheia. Os seres humanos entretanto se humilham e rastejam na lama por um prato de comida suja. (Ibid., p. 14)

Sendo uma atitude tão desprezível, é natural que sirva como critério de escolha para sociabilidade. Aqui, não há espaço para a solidariedade e a convivência plural, pois é aconselhado não só a distinção, como o total afastamento de pessoas em situações sociais inferiores: "Fuja dos indivíduos fracassados ou em vias de fracassar. São contagiosos e perigosos" (ibid., p. 21; grifo meu). Tal conselho, no entanto, não é privilégio da obra analisada neste artigo. A ideia de que o fracasso pode ser contagioso, pelo contrário, é bastante frequente na autoajuda contemporânea.

\section{O imperativo do desempenho}

As premissas presentes nesse tipo de livro são dirigidas a todo o conjunto da população, não podendo delas escapar nem grupos específicos como, por exemplo, as pessoas com deficiência física, que, a todo momento, são motivadas a serem úteis, a despeito das mais imponentes limitações físicas que possam apresentar. Da mesma forma, os idosos também são incitados à lógica do desempenho: "O falso sucesso é achar que um minguado salário de aposentado significa ter vencido na vida. O verdadeiro sucesso é manter-se produtivo até os últimos dias de vida" (MORGAN, 1989, p. 26; grifo meu).

A preguiça, em qualquer faixa de idade, é encarada como o pior pecado capital, como o "agente empobrecedor mais poderoso que se conhece em todos os tempos" (ibid., p. 79). O termo aparece aqui, no entanto, com uma definição bastante elástica, tendo em vista o exemplo fornecido pelo autor:

Um homem que trabalhe das 5 da manhã às 5 da tarde numa pedreira com um martelo não pode ser taxado de preguiçoso total. Talvez a preguiça dele esteja no fato de não buscar o autoaperfeiçoamento, para, a partir daí, executar um trabalho mais produtivo e compensador. (Ibid., p. 79) 
Trabalhar por 12 horas em uma pedreira não é o suficiente para livrar o sujeito da alcunha de preguiçoso. É preciso buscar sempre mais. Acomodar-se em um emprego, seja ele qual for, é uma atitude sempre denunciada como um erro crucial. A mudança, nesse sentido, é vista como boa em si mesma; é preciso estar sempre em busca de desafios e crescimento, cenário identificado por autores como Sennett (2007) e Ehrenberg (1991), que destacam a insegurança do mercado de trabalho contemporâneo como incentivo à perene vigilância em relação ao próprio desempenho, uma fonte constante de ansiedade.

No livro de Morgan (1989), os próprios limites corporais são lamentados pelo autor como impeditivos da performance:

O desgaste da energia corporal obriga o corpo a parar o esforço para acumular novas forças, e este acúmulo é feito durante o sono. Assim sendo, o ser humano só deveria sentir sono quando estivesse totalmente esgotado, ou chegasse ao limite máximo de sua resistência. De certo modo, a sociedade moderna criou leis que limitam o período de trabalho para certas atividades. No passado, um trabalhador era obrigado a executar serviços por 10 ou mais horas seguidas. Nos dias atuais, este período diminuiu ainda mais, passando para 8 e 6 horas regulamentadas (...). Seu corpo [também] precisa ser alimentado corretamente e exercitado para produzir muito. (lbid., p. 102-103)

A mensagem passada pelo autor é que sempre é possível ir além do que julgamos ser nosso limite. "Se você sentir cansaço no final de um dia de trabalho, e achar que foi o máximo de suas energias, engana-se redondamente. Você será capaz de muito mais. Experimente!" (ibid., p. 107), afinal de contas, como diz o título do capítulo 18, "O trabalho nunca matou ninguém".

Ao longo dessa seção, o autor, de forma resumida, se dedica a fornecer dicas de como trabalhar muito sem morrer: "Para sua informação, saiba que cada pessoa tem um limite de energia diária, e ainda que esta fosse obrigada a trabalhar, chegaria o momento em que desmaiaria de cansaço" (ibid., p. 110).

Depois de ficarmos aliviados com a informação que o desmaio precederia nossa morte por exaustão, o autor continua: "Antes de morrer de tanto trabalhar, uma pessoa precisa ser completamente extenuada, levada ao extremo de suas forças" (ibid.), para completar com detalhamento fisiológico: "Neste caso, haverá um colapso do sistema nervoso, respiratório, cardíaco, etc." (ibid.).

Uma das características problemáticas dos livros de autoajuda é que eles descrevem um mundo em que virtualmente todos os leitores teriam a possibilidade de, ao menos, tentar aplicar os seus ensinamentos - ou seja, supõem que há, na sociedade, uma igualdade de condições que abriria a todos as mesmas oportunidades. Não que a estrutura social seja de todo negada, mas subjaz nesse discurso uma ode ao critério meritocrático, o mesmo que fundamenta o modelo de competição esportiva, no qual todos os jogadores disporiam, teoricamente, de uma mesma chance para competir. 
É nesse sentido que Ehrenberg (1991) argumenta sobre a existência de um culto à performance, ao falar sobre a influência cada vez maior exercida pelo esporte no mundo do trabalho, onde é possível identificar uma ênfase crescente sobre noções como competitividade, aventura, desempenho, tomada de riscos. Para o autor, esse discurso nasce no universo das corporações, mas posteriormente se espalha por todas as esferas da sociedade.

No capítulo 12, intitulado "Começe (sic) a Gostar de Dinheiro", o autor usa como epígrafe uma citação de Joseph Murphy que afirma, em outras palavras, que você (o livro é todo escrito em forma de vocativo) nasceu para ser rico, uma vez que Deus é o rico "dono deste planeta com tudo quanto existe nele, jazidas de ouro e diamante, riquezas infinitas" (MORGAN, 1989, p. 71) e você é seu legítimo herdeiro. "Basta que use o poder existente em si mesmo para atrair tudo que é seu por direito" (ibid.).

Nessa seção, o autor se dedica a disseminar uma mensagem muito frequente nos livros, a ideia de que as pessoas não devem se envergonhar ou se culpar por gostar de dinheiro e sim assumir esse sentimento e fazer disso um incentivo para buscá-lo incessantemente. Gostar de dinheiro aparece, assim, como condição sine qua non para obtê-lo: "as pessoas que menos gostam de dinheiro são os pobres. (...) As pessoas fracassadas financeiramente parecem detestar as riquezas e dizem, de boca cheia, que não gostam de muito dinheiro" (ibid., p. 72); "Afirmo que gostar de dinheiro é o primeiro grande passo para aumentar a conta bancária".

E quando se refere a dinheiro, o autor não está pensando apenas nos bens materiais que são adquiridos a partir dele. Em uma passagem que nos faz visualizar o Tio Patinhas mergulhando em sua piscina de moedinhas de ouro, Morgan faz questão de explicitar que o sentimento deve ser dirigido, também, ao dinheiro propriamente dito: "Esqueça, portanto, as outras coisas, pense no dinheiro em si. Goste dele, ache bonito as notas, as moedas. Colecione-as aos milhões" (ibid., p. 73).

\section{Considerações finais}

Embora não seja, decerto, a única formadora da mentalidade contemporânea, a autoajuda desempenha um papel fundamental na produção da subjetividade a partir da qual julgamos nossa própria performance no mundo e avaliamos os sucessos e fracassos dos outros. Ao ajudar a difundir uma problemática divisão da sociedade entre as figuras do vencedor e do fracassado, esse filão editorial torna ainda mais incisivo o discurso a respeito da responsabilização dos indivíduos sobre suas próprias trajetórias, o que serve, em última instância, à diminuição da atribuição coletiva e política dos transtornos e aflições compartilhados socialmente, além de incitar o comprometimento com uma série de práticas, principalmente ligadas ao mundo do trabalho, que visam à "vitória", entendida como a consecução de uma vida bem-sucedida em todos os aspectos, sobretudo financeiro, como o único objetivo, como um fim em si mesmo. 
Se o fracasso não pode estar no campo das possibilidades, onde ele parece sempre figurar, temos um problema. Mas esse não é o único. Vários autores que se dedicam a analisar a contemporaneidade falam do mal-estar causado pela exigência do self ideal que cria a sensação de uma linha de chegada que está sempre se afastando. Ao mesmo tempo, esse mesmo imaginário estipula a linha de chegada como o único fim possível, já que é importante ser um vencedor, e quem vence não apenas completou a prova, mas chegou em primeiro lugar, o que nos leva a uma situação paradoxal. "O importante é competir" parece não fazer mais tanto sentido, talvez porque competir já não seja uma mera opção. Em momento algum, todavia, é questionado o fato de não caber todo mundo no pódio.

Mayka Castellano é pós-doutoranda no PPGCOM da Escola de Comunicação da Universidade Federal do Rio de Janeiro (ECO/UFRJ) na linha Mídia e Mediações Socioculturais. Doutora em Comunicação e Cultura pela mesma instituição.

maykacastellano@gmail.com

\section{Referências}

BOURDIEU, P. A distinção: crítica social do julgamento. São Paulo: Edusp; Porto Alegre: Zouk, 2007. CASTELLANO, M. Da importância do caráter ao imperativo da vitória: as transformações na literatura de autoajuda do século XIX aos dias atuais. COMUNICON, 4, São Paulo. Anais... São Paulo, ESPM/ SP, 2014a.

Sobre vencedores e fracassados: a cultura da autoajuda e o imaginário do sucesso. Tese (Doutorado em Comunicação e Cultura). Universidade Federal do Rio de Janeiro, Rio de Janeiro, 2014b.

CATANO, J. V. Ragged dicks. Masculinity, steel, and the rhetoric of the self-made man. Carbondale and Edwardsville: Southern Illinois University Press, 2001.

DECKER, J. L. Made in America. Self-styled success from Horatio Alger to Oprah Winfrey. Minneapolis: University of Minnesota Press, 1997.

EHRENBERG, A. Le culte de la performance. Paris: Calmann-Lévy, 1991.

FOUCAULT, M. Historia da sexualidade III: o cuidado de si. Rio de Janeiro: Graal, 1985.

. O sujeito e o poder. In: DREYFUS, H; RABINOW, P. (orgs.). Michel Foucault, uma trajetória filosófica: para além do estruturalismo e da hermenêutica. Rio de Janeiro: Forense Universitária, 1995, p. 231-249.

. A vida dos homens infames. In: Estratégia, poder-saber. Ditos e escritos IV. Rio de Janeiro: Forense Universitária, 2003, p. 203-222.

MORGAN, T. Só é fracassado quem quer. São Paulo: Ediouro, 1989. 
SANDAGE, S. A. Born Losers: a history of failure in America. Cambridge: Harvard University Press, 2005.

SENNETT, R. A corrosão do caráter. Conseqüências pessoais do trabalho no novo capitalismo. Rio de Janeiro: Record, 2007.

SOUZA, J. A construção social da subcidadania: para uma sociologia política da modernidade periférica. Belo Horizonte: UFMG; Rio de Janeiro: IUPERJ, 2006.

WEBER, M. A ética protestante e o espírito do capitalismo. São Paulo: Martin Claret, 1999.

Artigo recebido em julho e aprovado em setembro de 2014. 